\section{Restless legs: \\ Do they keep you awake?}

Kimberly Hutchison, MD; Ramon Cuevas, MD; and Janet Jankowiak, MD goline. In this issue of Neurology, a group of German researchers studied cabergoline to treat people with RLS. ${ }^{1}$ get as much sleep as they need. Lack of sleep, or lack of good quality sleep, affects the way we think, our relations with others, and our general health. There are many reasons and causes for poor sleep, including outside causes (loud noises) and internal causes (pain, stress, breathing trouble, or brain injury). Some sleep problems occur with body movements that are not under the person's control. One such problem is called restless legs syndrome (RLS). As the name implies, people with this problem have an irresistible urge to move due to uncomfortable feelings in their legs. They get some relief from the discomfort by moving, walking or stretching. The problem is worse at night or when the person tries to rest, which therefore makes sleeping difficult. RLS is common, but often not recognized. It may affect as many as 8 to $10 \%$ of the population. More information about restless legs can be found on the next page (About Restless Legs Syndrome).

Fortunately, there are medications to treat the uncomfortable feelings in RLS, although they do not cure the problem. Many of the medicines used for RLS symptoms are also used in Parkinson disease (PD), a common neurological condition with shaking, slow movements, and a shuffling slow walk. Interestingly, people with PD also have sleep problems. One of the medications used for PD is caber-
Stiasny-Kolster et al. ${ }^{1}$ studied the effectiveness and safety of different doses of cabergoline in patients with moderate to severe RLS symptoms. A total of 85 patients were divided into four groups. Each group was treated with a different dose of cabergoline: zero (placebo or look-alike pill with no medication), $0.5 \mathrm{mg}, 1.0 \mathrm{mg}$, or $2.0 \mathrm{mg}$. Before and after a 5-week treatment period, patients rated their symptoms and answered questions about their sleep using a standardized rating scale. The patients receiving cabergoline reported a greater improvement in RLS symptoms. Additionally, patients receiving the higher doses of medicine reported more relief than those receiving less medicine. After the 5-week study period, all patients were allowed to continue the medication and increase the dose to the most effective and besttolerated level for them. They were followed for up to 1 year. The average dose of cabergoline was 2.2 mg per day, slightly higher than the largest dose used during the first 5 -week period. For most of these patients, the improvement in daytime, nighttime, and sleep symptoms lasted throughout the year.

The safety of cabergoline was also studied. About one-third of the patients reported side effects, with the most common being nausea, fatigue, and dizziness. Over the course of the year, 11 of the 85 patients $(12.9 \%)$ stopped taking the medicine because of bothersome side effects. Only one serious side effect occurred; one patient had hallucinations after taking the medicine for 6 months. No deaths were reported.

As mentioned, other drugs used for PD are also effective for RLS. However, cabergoline is unique in this class of drugs because it lasts longer in the body. This enables a person to take just one dose daily. When using some of the shorteracting medications of this class for RLS it was noted that RLS symptoms improve within the first 4 to 6 hours of sleep, but may not be adequately controlled for the whole night. In some patients, RLS symptoms may shift from nighttime to the early evening or daytime, and become more intense or involve other body parts. This situation is called augmentation. With cabergoline, a few patients developed augmentation, but most often RLS symptoms improved after increasing the cabergoline dose.

In summary, Stiasny-Kolster et al. ${ }^{1}$ have shown that cabergoline, a medication already approved for the treatment of PD, is effective and generally well tolerated in patients with RLS symptoms. People troubled with uncomfortable feelings in their legs that cause an urge to move and disrupt their sleep, should contact a neurologist regarding possible RLS. A more restful night sleep is possible. 


\section{What is RLS?}

RLS is a curious neurological disorder marked by an irresistible urge to move due to strange sensations, most commonly in the legs. These uncomfortable sensations may be described as tingling, burning, aching, grabbing, or a "creepy-crawly" feeling analogous to worms crawling underneath the skin. These feelings are usually associated with an urge to move, typically by walking around, rocking, shaking, or stretching. The different movements that patients choose to reduce their discomfort are under voluntary control and can be suppressed. However, suppression may greatly increase the discomfort. Patients with RLS also may have involuntary movements of the legs. Typically these are brisk movements with a sudden jerk of the leg. What makes RLS unique is that these uncomfortable feelings are worsened by rest, lying down or sitting, and significantly improved by movement. Symptoms of RLS are typically worse in the evening and at night, which may interfere with falling asleep or staying asleep.

\section{What causes RLS?}

It is estimated that up to $10 \%$ of the population in the US is affected by RLS. Middle-aged adults and the elderly are most commonly affected, although cases involving children and adolescents also occur. Symptoms generally get worse over time. In about half of the cases, RLS runs in families. It is frequently passed from parent to child and equally affects men and women. In other cases, it is associated with certain medical conditions, like anemia, diabetes, kidney disease, or pregnancy. RLS may first come on or get worse during pregnancy. However, within weeks after delivery the symptoms may go away and not reappear for many years. Caffeine and certain drugs used to treat depression or vomiting have also been noted to cause RLS. The exact cause of RLS is unknown; however, it may be related to a problem with dopamine. Dopamine is a natural brain chemical involved in controlling movements. A decrease in dopamine is believed to be the cause of PD. Because of this relationship, many medicines used in PD are also used in RLS.

\section{How is RLS recognized?}

RLS is considered a sleep disorder because it interferes with sleep and causes sleep deprivation. Like many sleep disorders it is often under-reported by patients and often not recognized by doctors. Diagnosis of RLS is mainly based on information given by the patient or the patient's bed partner regarding sleep problems. In addition, a sleep study known as a polysomnogram may help with the diagnosis. While the patient sleeps special devices (which do not hurt) record sleeping patterns, breathing, oxygen levels, and movements. In 70 to $90 \%$ of patients with RLS, the sleep study will show an associated condition called periodic limb movements of sleep (PLMS). These movements are repetitive contractions of the legs that typically recur at intervals of 15 to 40 seconds during sleep. PLMS are particularly common in the elderly; more than $30 \%$ of people over age 65 have them. In fact, $70 \%$ to $80 \%$ of elderly people have more than five periodic limb movements per hour of sleep on some nights. Because of the increase of PLMS with age, a finding of PLMS on a sleep study is more strongly suggestive of RLS in young people.

\section{What treatment is there for RLS?}

Several different types of medications are used for the treatment of RLS. Carbidopa/levodopa, pramipexole and ropinirole-medications also used for the treatment of PD-are commonly used and highly effective. The recent study by Stiasny-Kolster et al. ${ }^{1}$ suggests that another drug in this same class, cabergoline, may also be promising. Alternative classes of medicine include certain types of sedatives (for example, clonazepam), certain drugs used to control convulsions (for example, carbamazepine or gabapentin), and for severe cases, narcotics (for example, oxycodone or morphine). An evaluation with a neurologist will help in finding the best individual medical treatment. Talk with your health care provider if you are having difficulty sleeping. A good night's sleep is important for good health.

\section{For more information}

Restless Legs Foundation www.rls.org

National Institute of Neurological Disorders and Stroke (NINDS) www.ninds.nih.gov/health_and_ medical/disorders/restless_doc. $\bar{h}$ tm

\section{National Sleep Foundation www.sleepfoundation.org/ publications/fact_rls.cfm}

\section{Reference}

1. Stiasny-Kolster K, Benes H, Peglau I, et al. Effective cabergoline treatment in idiopathic restless legs syndrome. Neurology 2004;63: 2272-2279. 


\title{
Neurology
}

\author{
Restless legs: Do they keep you awake? \\ Kimberly Hutchison, Ramon Cuevas and Janet Jankowiak \\ Neurology 2004;63;E21-E22 \\ DOI 10.1212/WNL.63.12.E21
}

This information is current as of December 28, 2004

\section{Updated Information \&} Services

References

Permissions \& Licensing

Reprints including high resolution figures, can be found at: http://n.neurology.org/content/63/12/E21.full

This article cites 1 articles, 1 of which you can access for free at: http://n.neurology.org/content/63/12/E21.full\#ref-list-1

Information about reproducing this article in parts (figures,tables) or in its entirety can be found online at:

http://www.neurology.org/about/about_the_journal\#permissions

Information about ordering reprints can be found online: http://n.neurology.org/subscribers/advertise

Neurology ${ }^{\circledR}$ is the official journal of the American Academy of Neurology. Published continuously since 1951, it is now a weekly with 48 issues per year. Copyright . All rights reserved. Print ISSN: 0028-3878. Online ISSN: 1526-632X.

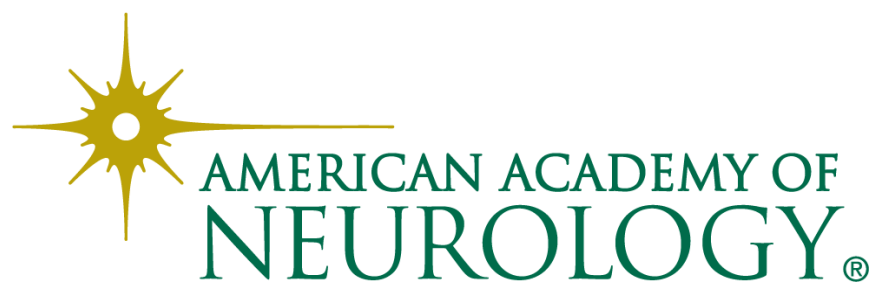

